\title{
The Impact of Brand Trust on Physician's Prescription Decision Towards Prothrombin Complex Concentrate with a Special Reference to Octaplex $\mathbb{R}$
}

\author{
D. R. G. Perera ${ }^{1} \&$ W. M. C. Bandara Wanninayake ${ }^{2}$ \\ ${ }^{1}$ School of Management, Cardiff Metropolitan University, Cardiff, UK \\ ${ }^{2}$ Department of Marketing Management, Faculty of Commerce and Management Studies, University of \\ Kelaniya, Sri Lanka \\ Correspondence: D. R. G. Perera, School of Management, Cardiff Metropolitan University, Cardiff, UK. Tel: \\ 947-7234-3075. E-mail: D.Perera29@outlook.cardiffmet.ac.uk
}

Received: September 7, 2019

Accepted: September 16, 2019

Online Published: September 29, 2019

doi:10.5539/ass.v15n10p1

URL: https://doi.org/10.5539/ass.v15n10p1

\begin{abstract}
Management of Hemostasis is an integral role for any Intensivist in assurance of recovery of a hemorrhage patient who is often treated in an ICU, and building trust of a product segment related to such vital treatment will undoubtedly hold an utmost importance. Yet in researches and articles in current Medical Marketing setup it is found to be very limited, and in the case of Biological and Bio-Similar Marketing its almost non-existence. The purpose of this research paper is to investigate and prove the significant positive impact of Brand Trust on Physicians Prescription Decision and Moderation impact powered by the synergy of Relationship Marketing. The research consists of data which was collected via online questionnaire and captured the data required from the target sample cohort which is distributed via respective specialized academic colleges of their representation through email and filed online by the participants of quantitative research. Moreover, two of the main key opinion leaders (KOLs) were interviewed and qualitative data were summarized. The collected data were analyzed using Structural Equation Modeling (SEM) procedures to reach meaningful conclusions. Thereby the study proves the significant positive impact of Brand Trust on Physicians Prescription Decision and Moderation impact which synergized by Relationship Marketing. The study is an original contribution to the field of Marketing in Biological and Pharmaceutical Industry. The proposed relationships are based on Brand Trust, Physician's Prescription Decision and Relationship Marketing. Furthermore, the Moderating effect of Relationship Marketing on the relationship between Brand Trust and Physician's Prescription Decision is unique to this study.
\end{abstract}

Keywords: brand trust, relationship marketing, biological, bio-similar and pharmaceutical industry, prescription decision

\section{Introduction}

The Healthcare sector is very vital and integral part of countries' citizens health and well-being, as its explained in the country's healthcare development policy, Sri Lanka maintains a significant degree of good reputation for its cost-free health policy which was shown much commitment by all the government which were in power since its implementation. "Success of Sri Lanka's health sector is mainly dependent on its efficient public delivery process, which consists of two major components, namely both curative and preventive care delivered at a significantly minimal expenditure. The government provided healthcare facilities at absolute no cost to all its citizens, by enlarge in all prophylactic care and many in-patient therapies" (The Economist, 2014). Because of the said policy Sri Lanka enable itself to be par with the healthcare sector markers that are of an established country and it mimics the NHS, UK. As far as healthcare markers are concerned Sri Lanka has established a life span of above seventy-eight years for females and seventy-two years for males, followed by newborn death level of 8.2 for every 1000 live childbirths. In addition, what is substantial with said statistics its that simply because it has been accomplished with government health expenses as low as 1.66 percent of Gross National Production, and the number of medical officers per 100,000 population remained 87 where number of hospitals was 631, followed by hospital beds count which reached 80,581 giving in a hospital beds per 1,000 population 3.8 which 
remained a significant milestone. (Ministry of Health, Annual Health Bulletin 2015)

Currently, Sri Lankan healthcare sector comprises of two main parts, the public sector which usually cater to the vast majority of the countries' population, followed by a powerful and reasonably competitive private market. Furthermore, in the aspect of purchase of drugs and services associated with healthcare in the public sector, it is done via tendering processes by MSD (Medical Suppliers Division) and by the procurement arm for the government establishments the SPC (State Pharmaceutical Corporation).

Moreover, Total Pharma market in Sri Lanka was summed over LKR 101 billion in 2016.followed by total health care industry found to be valued at LKR 298 billion as at year 2016 (BMI Report 2017). Over 83 percent of the total pharmaceutical requirement of Sri Lanka is catered through Foreign pharmaceutical manufacturers and suppliers and the balance 17 percent is manufactured locally (IMF Data, 2014). Where the Multinational and Foreign pharmaceutical firms are found to dominate the market place. However, current government policy improvements and changes can motivate us to think otherwise, as they simply by initiated a change in drug pricing policy where the government controlled almost forty two crucial medicines in the initial phase of execution, followed by another thirty two drugs in the month of August 2018, as an outcome, numerous multinational suppliers were forced by legislation to cut down their price ranges substantially, which even led fewer businesses resulting in closing down its operations in the country. It's interesting to understand the changes in behaviour of Sri Lankan Pharmaceutical Markets with the influence of Price control regulated by government policies. Introduction of price control in 2016 impacted 28 percent of Sri Lanka Pharmaceutical Market Though value de-growth of (-7) percent, although the unit growth was 9 percent in whole, this impacted badly on the pharmaceutical industry's overall growth resulting in many insecurities to the stakeholders and employees followed by support services of the said industry.

The product focused on the research is a biologically extracted clotting factor complex, also known as "Prothrombin Complex Concentrate (PCC)" which was medically suggested to invert the effect of hemorrhaging induced by drugs like Warfarin (Vitamin K Antagonist) which is utilized post cardiac bypass surgery to reduce the risk of clotting (Thrombosis) related mortalities in humans, moreover in Sri Lankan context it is of high importance as Sri Lanka has a rapid ageing population. Followed by high percentage growth of non-communicable illnesses such as cardiovascular disorder primarily due to high cholesterol levels which confirms very high possibility of leading to cardiac by-pass or such associated procedures (Swiss Resigma no 3, 2016). Additionally, in the latest studies PCC was discovered to be recommended additional in number of symptoms such as in General surgeries, cardiac surgeries, neurological surgeries, abdominal surgeries, orthopedic surgeries and in ICH (intra cranial haemorrhage) as all these procedure/conditions are associate with high amounts of Haemorrhage. Moreover, PCC supplements at an event there is a loss of coagulating factors which are in the blood and thereby holdup the coagulation time that can affect in haemorrhage. So, to supplement, the coagulation, PCC is medically indicated because it gives ready-made coagulation and thereby manage the haemorrhage. In this light of importance of the product segment the investigators has taken interest to analyse the factors associated and affecting towards the prescription choice of a doctor to a PCC therapy (Carvalho, Rodrigues, Conceição, Galvão, \& Ribeiro, 2012)

Furthermore, the Brand in specific which is researched by investigators to carry out the mentioned study is named Octaplex which is a Human Derived Prothrombin/Coagulation Factor Complex which contains 4 Factors (Factor IX, Factor X and Factor II, Factor VII,) which plays an extremely significant role in regulating coagulation by supporting the coagulation cascade of the human body which handles the haemorrhaging. Octaplex is an globally renown brand which is greatly trusted globally by all medical professionals, which is produced by an Multinational Supplier and a manufacturer referred to as OctaPharma G.M.B.H, which is a firm that lengthen its competence in large variety of biological and plasma extracted brands/products throughout years (Hoffer et al., 2005).

\section{Literature Review}

\subsection{Brand Trust}

In Speakman (1988), it is described the trust could be developed as an establishment for a long-lasting relationship with customers, additional to which the brand trust is an extremely essential feature of a brand in the improvement of shared association between two sections (Bansal \& Taylor, 2005) furthermore it will decrease cost of the companies simply because of customer loyalty and maintenance programs. It likewise can be abbreviated as the observed trust in the direction of a specific service supplier in the feature of support brands. (Holbrrok \& Chuadri, 2001) It created via customers anticipated result and expected total of benefits (Delgado, 2004) it can easily be explained as a by impact of dependability of the actual Brand.it happens from situations 
whenever companies can offer higher customer valuation in the direction of buyers. It elaborates on the companies guaranteed and supplied along with their services above customers anticipations. If customers' needs are able to be pleased from the company, thus that will allow a consumer to retain trustworthiness of the brand that mirror a feasible competing benefit for the company. Nevertheless, Ria (2008) verifies that a brand intention described always yet another aspect of brand trust. Brand intention is a situation while firms can reveal on consumers' anticipations. When customers create trust in a specific brand that indicates the stated customers would certainly acquire total probable risks toward the product or service. Through the way of raising brand trust, companies could gear its selves to create themselves occur in the extremely competitive marketplace and reduce costs for marketing and promoting campaigns.

Lee and Lau (1999) elaborate that there could be 3 elements as originator of brand trust, i.e. brand attribute, company characteristics and purchaser or consumer attributes. While company has predominant features, e.g. higher to competitors, reduced cost, outstanding service, a brand might also reveal its individual attributes, e.g. safe, best brand, higher quality as well. Also, there is an association amongst purchaser and brand features. When their attributes satisfy each other, after that it will create exceptional brand trust.

Moreover, Brand trust might be one that tends to make a crucial problem that customer considers while creating a purchasing choice and it has been often recognized as assurance on Brand (Alessandro et al., 2012). Brand trust has been analysed via numerous elements in marketing articles and frequently its conceptual framework is based on one dimensional point of view (Hawass, 2013). Holbrook and Chudri (2001), by this element have made concept that brand trust as a path that's all through- out also very carefully regarded. It is considered as an essential expectancy that a customer has on the dependability of brand. Brand trust exhibiting this single dimensional element is at times regarded as consumer's calculative perception about the brand technical attribute (Holbrook \& Chudri, 2001). In any case, brand trust has advanced above many years and is not only been influenced by prospects about the product attributes or act but consists of emotional checks as well (Becerra \& Badrinarayanan, 2013) often brand trust is found to be influenced by ethnocentrism (Wanninayake \& Dissanayake, 2009). In this aspect, Ballester and Aleman (2001) argued that brand trust is a multi-dimensional concept with two primary elements, by name brand dependability and brand intent. Brand dependability echoes the client's self-confidence on brand's practical attributes while the brand intent signifies the decent objective of the brand with fine detail to customers' need on wellbeing (Ballester \& Aleman, 2005). Brand intention is responsible for emotional attribute and recreates the assurance that brand could compensation a client in some way for any feasible issues relating to the product (Hawass, 2013). Furthermore, helping this viewpoint, Folse et al. (2013) have declared that brand is no longer a product but has emerged as a partner in the customer-brand relationship. Brand trust has been considered as an essential element of brand equity and noted to play an essential role in brand buying behaviours (Luk \& Yip, 2008). Brand trust is one with trusting objectives plays a supportive role in the buying decision process by creating optimistic viewpoint on the brand (Ballester, 2003). Title role of brand trust has formulated more important once the buying situation is a risky and expensive one (Garbarino \& Johnson, 1999; Hawass, 2013). With the said conditions, brand trust aids as an emotional contrivance via which customers decrease the unclear risks related with Brands (Matzler et al., 2008; Hawass, 2013). Brand trust is to be also been recognized as benefit for customer conduct such as brand buying conduct (Luk \& Yip, 2008; D’Alessandro et al., 2012), brand loyalty (Paulssen et al., 2014) and brand equity (Ballester and Aleman, 2005). These results essential to brands to reveal a prominence of promise and directions greater market segment and exceptional values in the market (Ruparelia et al., 2010). Drug-related and vital role played by brand trust in purchasing outcomes has activated researchers to progress discover its relationship with diverse concepts. For example, Sung and Kim (2010) have evaluated the relationship among ones like brand personality character types and brand trust and decided that genuineness and roughness has a much better outcome on brand trust.

Additional, readings in the part of interactive relationship have hypothesized predictability, capability and reliability as the key forecasters of trusting concepts in brand (Rempel et al., 1985; Andaleeb \& Anwar, 1996; Luk \& Yip, 2008). Hawass (2013) in said reading associated with new brands have stated about the relationship within brand trust and customers' concerns toward the obvious risks. Rampl and Kenning (2014) have continuous the study of brand trust to firm branding through is lead with the relationship between brand trust and firms' personality. Subsequent to this way of thinking, it is rational to determine that the brand trust is calculated by both investigators and marketers as a substantial component in customer-brand relationship. However, it is only not too long ago that marketing literature developed the importance of determining the dimensions of brand trust since trust in a product brand could be different from trust in an interpersonal relationship (Luk \& Yip, 2008). Few marketing studies have worked towards discovering intellectual and efficient scopes of brand trust. 
Johnson and Grayson (2005) in their study of service interactions have characterized intellectual and affective as two dimensions of trust. Their conceptualization of trust as having cognitive and affective dimensions has been based on well-established assumptive preceding from the social psychology work of Lewis and Weigert (1985). Owing to the richness and relevance of Johnson and Grayson's framework, it has been adopted as the guideline to conceptualize and determine brand trust in this study as presence of both technological and emotional matters of brand trust is critical for causing consumer's attitude and brand-related behaviours (Elliott \& Yannopoulou, 2007; Becerra \& Badrinarayanan, 2013) in the context of high-risk product classification. These texts confirm the pure significance of laying down Brand trust as a primary independent variable in the said product category. As it could be contended Brand Trust may play a significant role in prescribing a biological brand such as Octaplex®.

\subsection{Physician's Prescription Decision}

Physician's prescription choice in this research means to assortment of a branded drug prepared without logical impact, and an option recognized to impact doctors' decision taking when recommending (Zerzan et al., 2011) From an economical philosophical point of view, this could turn out to be debated that behaviour perseverance is a brands reliability created by influential pharmaceutic promotions (Waheed et al., 2011). In contemporary practices, physicians, throughout medical function, may develop few strategies from which to exercise handling the medications. This traditional exercise has been consisting to be matter by which the persistence of the behaviour (Zerzan, et al., 2011). Therefore, habit persistency might solely be inspired by the budget of choice-made (Karunanayake \& Wanninayake, 2015), it's crucial for the physician to build behaviour to reduce the stress of view making connected to the action of prescribing. Aspect of routine tenaciousness as a strong stimulus on doctor prescribing is not unforeseen when bearing in mind the problems of prescribing choice. Venkataraman (2011), verifies it is well apparent that there could be significant habit tenacity in doctors' decision making. Also, it's found routine tenacity to be responsive to detailing and sampling (Janakiraman et al., 2008). Thereby, it can fairly be argued that physician-level practice tenacity must be conquering for the marketing work to have an expressive impact on doctors' prescribing behaviour. However, it could be argued that physician-level behaviour persistence moderates any impact made by marketing techniques on physician prescription decision. And therefore, conducting further organized studies are of high significance in the given product framework.

\subsection{Role of Relationship Marketing as a Moderator}

It is explained in the overview portion, physicians continued to be the greatest significant aimed customers for the Biological companies. Whenever in comparison with traditional marketing sages, Physicians have not discovered to be the end customers of the products, however, their part is of excessive importance of that of patients, as in numerous of the conditions they produce the demand of products or biological medicines. For this cause, relationship marketing must be researched towards this focus on customers. "In this element the definition of key decision maker changes: we are not able to talk about precise sales, but the initiators of sales. At times the target client is not the doctor who writes prescription medications, but the opinion leaders who impact their acquaintances to do so" (Tsang, 2001). At current to reveal the prescription behaviour of physicians is the essential obligation for the pharmaceutical or biological company. The data regarding the prescription medications from the past and the info about the desires, needs, motivations of the practice can become a competitive advantage for the company that recognizes how to use it in generating their marketing efforts (Vanderveer, 2002). Pharmaceutical marketing scientists understood that success of a particular brand forecasted mainly on physicians' endorsement behavioural habits (change on to an alternative brand) of the physician (Barnes, 2003). Tracking the prescribing process of each doctor needs an appropriate technology for the modern-day companies. All these pieces of info correspond to individual marketing plans. It is found that physicians turn out to be the most substantial players in pharma and biological sales. The prescriptions that they produce control which drug will be utilized by the patients. Impacting the physicians is the greatest efficient \& important key to raise pharma sales revenues. pharma companies try to influence prescription habits of doctors in authorization of their brand by submitting of various types of promo tools such as medical samples, gifts and Academic / individual sponsorships (Taneja \& Arora, 2006). Several organized assessments have identified that pharma sector financing of drug related studies was connected with conclusions which are beneficial to the sponsor's product which gave the funding or grant (Bekelman 2003). There are many ways that the business could support a study/trial, together with mono-source sponsorship, collaborative funding, also providing free of charge pharmaceutical drugs or medical devices. With reference to the pharma marketing exercising, Honka and Manchanda (2005). Often factors such as service quality and customer service will be provided via relationship marketing (Wanninayake \& Dissanayake 2007). Ahearne et al. (1999) states that "much pharmaceutical marketing efforts is directed at doctors and customers with the goal of facilitating market exchanges that 
optimize the company's return on marketing investments". With the conversations herewith, it is evident the relationship marketing must be additional studied guide to the given context of this study.

Linked on to brand trust, Relationship Marketing applications too effects favourably to brand trust. Relationship marketing applications demonstrated in customization program will produce client total satisfaction. "Client pleasure is indicated into two sorts such as satisfaction leads to patronage and to positively impacting word of mouth" (Lam, Shankar, Erramilli, \& Murthy, 2004). The fact that consumer satisfaction extremely may make way to some purchasing patronage, means it will improve brand trust with respect to dependence processes. Verhoef (2005) recognized that Relationship marketing applications will produce an influencing dedication which can make way to brand trust. However, there is not enough articles to intricate the moderation of same also in the context of biological or pharmaceutic brand marketing, thereby this study will enable the investigator to define and may create way to lay down insights for future studies.

\section{Hypothesis Development}

The Brand Trust has been found to be a very critical attribute when deciding to prescribe a product once or respectively for a disease or a therapeutic indication that is very much into intensive and life-threatening in nature, in said kind of situations a consultant or a doctor would not like to have doubts in it bringing out desired cure rate or predicted or desired treatment outcomes. Moreover, since Octaplex (PCC) the product related to this study is very much a brand which has said attributes and represents said critical and intensive treatment protocols the below framework is laid down. The models such as Hegner and Jevons, (2016); Becerra and Badrinarayanan, (1992) were considered keeping developing variables like Brand Trust which has cross-cultural validity which confirms that irrespective to Demographic, Geographic or Ethnic factors the Sub Dimensions and Variable representation was same thereby the Independent variable of the study is clustered on to these sub-dimensions, per cent which is namely Competence, Predictability, Benoloevence/ Integrity. And Moderating Variable was set as Relationship Marketing which is derived from the studies such as Geethanga and Dissanayake (2014), Janakiraman et al. (2008) which reflects medical representatives, and drug marketing companies contribution representation toward moderation in the said Conceptual framework.

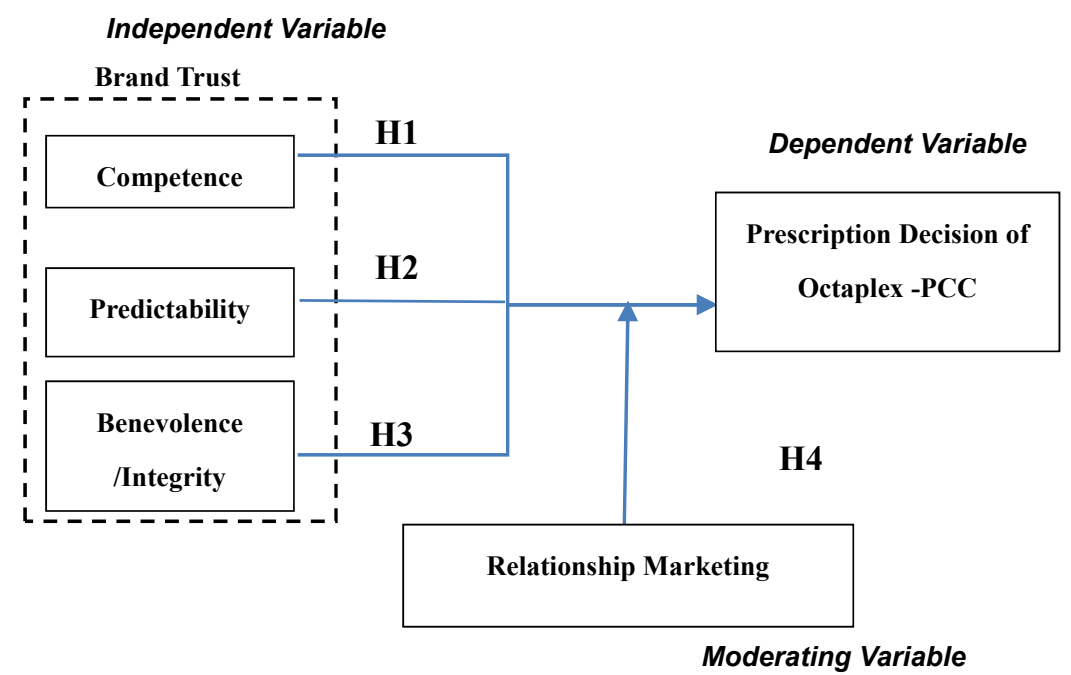

Figure 1. Theoretical framework

The in-depth analysis of the literature suggests that the brand trust positively affects customer satisfaction, purchase decision and in relation with this study its physicians' prescription decision which is ultimately the customer satisfaction or purchase decision outcome (Hegner \& Jevons, 2016; Becerra \& Badrinarayanan, 1992). And Studies such as Delgado-Ballester 2014 - which define brand trust's sub-dimensions to be competence, predictability, benevolence/integrity not only confirming same also that it is seen same thought many countries, ethnicities, age groups and many product categories which are of concrete evidence to the below-mentioned hypotheses which are in the current study. Thereby it is hypothized the Brand Trust in form of its respective sub-dimensions competence, predictability, benevolence/integrity are positively impacted in making physicians prescription decision on Prothrombin Complex Concentrate (Octaplex)

H1- Competence has a positive impact on Prescription Decision of PCC 


\section{H2- Predictability has a positive impact on Prescription Decision of PCC}

\section{H3- Benevolence /Integrity has a positive impact on Prescription Decision of PCC}

Representation of relationship marketing is a vital element in this study as relationship marketing directly influence purchase intention of a product although a number of other variables, such as duration, conflict, competence and dependence/independence, have also been investigated with respect to relationship marketing, these studies generally find in turn some direct or indirect link to trust, commitment or communications (Aijo, 1996; Anderson \& Narus, 1990; Berry, 1995; Ganesan, 1994; Grönroos, 1994a; Gummesson, 1994a; Leuthesser \& Kohli, 1995; Lewin \& Johnston, 1997; O'Malley \& Tynan, 2000; Ravald \& Grönroos, 1996; Sirdeshmukh, Singh, \& Sabol, 2002). These studies demonstrate the importance of trust, commitment and communications quality to relationship initiation and development. Some of the antecedents found to influence the trust, commitment and communications constructs in the relationship marketing research and the effect on relationship outcomes. Thereby in this study, the link of relationship marketing is hypothized to positively impact moderation. Further studies like (Geethanga \& Dissanayake, 2014; Janakiraman et al., 2008) confirms its connection in the form of medical representatives' rapport, CMEs, company trust as possible dimensions. And with these comprehensive literature search has contributed to the below-mentioned moderation hypnotized.

H4- Relationship Marketing has a Moderating effect on Relationship between Brand Trust and Prescription Decision of PCC.

\section{Research Methods Data Collection and Sample}

The said research conducted to define the scope of Brand Trust contributing to a physician's prescription decision with the moderating assistance of relationship marketing toward Prothrombin complex concentrates with special reference to Octaplex.

The data collection is conducted in all doctor specialties which are critical of indications which can be prescribed with Prothrombin Complex Concentrate (Octaplex), which includes Anaesthesia, Cardiology, Cardiothoracic Surgery, Gastroenterological Surgery, General Medicine, General Surgery, Haematology, Neurosurgery, Obstetrics and Gynaecology Orthopaedic Surgery, Thoracic Surgery, Transfusion Medicine Thoracic Surgery, Transfusion General Medicine. Furthermore, its strategized in a way to collect all information within the set model of conceptualization to the analysis of set hypotheses. The Data collection is done via an online email distributed E-Questionnaire which comprise of 33 questions keeping with the studied variables and sub-variables with an addition of demographic questions to define the attributes which the study sample belonging on to with, moreover the said study is focused at the above mentioned all specialities within the count of sample size generated by sample size calculator. And quota, non-probability sampling was selected as the sampling method as it will support to include all specialities critical of research representing propositionally towards their own true representation as a percentage from the total cohort. In addition, two focused interviews will be conducted by the researcher to re-clarify the data collection to a greater extent.

Data Validity is measured by using methods such as Cronbach Alfa testing, and overall data analysis is done via IBM SPSS version 24.0. Been understood the difficulty in retrieving information in Brand Trust in relation with limited time frame available, a cross-sectional study decided as a more practical and suitable than a longitudinal study. Although longitudinal studies provide the ability to observe and test parameters over a larger time frame repeatedly in the same study cohort. The advantage of the longitudinal study is that complex variables can be developed over time (e.g. Trust) could be better captured and link associate more steadily (Bowen \& Wiersema, 1999). However cross-sectional study would limit itself to capture an impact to a shorter period (MacCallum \& Austin, 2000; Pinsonneault \& Kraemer, 1993). Although the said limitations were there a cross-sectional study is selected looking at the time, financing and other critical limitations felt by the researcher (2001; Pinsonneault \& Kraemer, 1993; Scandura \& Williams, 2000). This Study is designed as per biological marketing niche were not having studied enough in the discipline of marketing, and current study layout framework vital of said industry. Mix methods are used such as Focused Interviews and questioners which are derived from earlier research models which are conducted by (Hegner \& Jevons, 2016; Becerra \& Badrinarayanan, 1992; Ballester \& Alemán, 2005) where dimensions of Brand Trust is measured with a similar structured questionnaire covering all elements and attributed mimicked towards same. Further Relationship Marketing is also established as a moderator and same is captured by models explained (Geethanga \& Dissanayake 2014; Janakiraman et al., 2008) which are found be similar in constructs. Internet surveys are becoming more popular but suffer from a number of issues including (Couper, Kapteya, Schonlau, \& Winter, 2007; Ranchhod \& Zhou, 2001; Simsek \& Veiga, 2001) limited or low response rate and concern towards if the participant is the same which is the holder of email address. However direct E-mail still holds to be the most efficient and cost-effective ways of operationalizing. 
The said research construed as mix method based, non-probability quota sampled, cross-sectional study. Moreover, it uses 5-point Likert scale question base 33 number questionnaire with demographic questions for identifying the sample population further.

The study E- Questionnaire was distributed as per the representation guideline formed for the specialities via emails the participants were facilitated to it fill online by use of Google forms. The total sample count of the E-Questionnaire which was distributed remained 264 numbers which are aligned with the requirement produced by sample calculator, whereas the researcher received with 221 filled and completed questioners contributing to approx. 83 per cent response rate. Out of the received filled questioners 11 were rejected due to the nature of answers been extreme ended. Thereby 210 numbers were taken as final suitable entries and same were tabulated for data analysis.

\section{Data Analysis and Results}

The collected data via questionnaire tabulated and coded as required. All variables in the study were analysed with use of Correlation method, Chi-Squared test, AVE and Composite Reliability Test, Assumption Testing (Independence, Normality, Homogeneity, Regression), ANOVA Test, R2 and Model Fit analysis, Moderation analysis for confirmation of aspects such as relationships, data validity etc. and thereby proven the hypothesis.

To prove the hypothesis of the proposed research the researcher use of Chi-Squared Test in the investigation of variables significantly associated with confirmation of such is a significant relationship between said variables the correlation method is suggested to be applied to investigate strong nature of the relationship.

SmartPls 3.0 is employed in the assessment of the impact of a moderating variable. To test moderation, the researcher would be looking for confirmation of the interaction effect between Brand Trust and Relationship Marketing and whether such an effect is significant in predicting physicians' prescription decision. The proposed statistical analysis has been done via data management software SPSS Statistics 24.0 and SmartPls 3.0.

After the said analysis is done the correlations and moderation can be understood, which will enable the researcher to laydown newer framework for biological marketing.

Table 1. Summary of Correlation Analysis

\begin{tabular}{lccc}
\hline & & Pearson Correlation & Sig (2-tailed) \\
\hline BT $\rightarrow$ PD & Brand Trust $\rightarrow$ Physicians Prescription Decision & $.637^{* *}$ & .000 \\
RM $\rightarrow$ PD & Relationship Marketing $\rightarrow$ Physicians Prescription Decision & $.524 * *$ & .000 \\
\hline
\end{tabular}

**. Correlation is significant at the 0.01 level (2-tailed).

As correlation is a bivariate analysis that measures the strength of association between two variables and the direction of the relationship.

According to the above table Brand Trust and Physicians Prescription Decision are confirmed to have positively significant correlation with significance of .637, whereas Brand Trust and Physicians Prescription Decision are confirmed to have positively significant correlation with significance of .524 respectively, Thereby, confirmation on both independent and dependent, moderator and dependent variables are found to be significantly with positive correlation.

Table 2. Summary of Chi-Square Analysis

\begin{tabular}{lccc}
\hline & & Chi-Square & Asymptotic Significance (2-sided) \\
\hline BT $\rightarrow$ PD & Brand Trust $\rightarrow$ Physicians Prescription Decision & $4.441 \mathrm{a}$ & .034 \\
RM $\rightarrow$ PD & Relationship Marketing $\rightarrow$ Physicians Prescription Decision & $4.341 \mathrm{a}$ & .032 \\
\hline
\end{tabular}

The above table confirms that data of independent and dependent variables are with a significant level of independence, where the Chi-Square value have been reported higher than 0.05 and asymptotic significance (2-sided) remained lesser than 0.05 respectively.

Similarly, data of moderator and dependent variables are with a significant level of independence. Where the Chi-Square value have been reported higher than 0.05 and asymptotic significance (2-sided) remained lesser than 0.05 respectively.

As per the Table 3, all variables have accounted above 0.7 Cronbach Alpha value which confirms an acceptable level of reliability. 
Table 3. Summary of Cronbach's Alpha, Composite Reliability and AVE

\begin{tabular}{ccccc}
\hline & & Cronbach's Alpha & Composite Reliability & Average Variance Extracted (AVE) \\
\hline BT & Brand Trust & 0.782 & 0.939534 & 0.504232 \\
RM & Relationship Marketing & 0.757 & 0.882548 & 0.620593 \\
PD & Physicians Prescription Decision & 0.717 & 0.995965 & 0.633333 \\
\hline
\end{tabular}

Furthermore, composite reliability is also tested. In all variables (Independent, Dependent, Moderator) composite reliability has measured to be above 0.7 which confirms the validity of data, The Average Variance Extracted (AVE) is calculated to confirm the validity measures of data. All variables recorded above 0.5 for Average Variance Extracted respectively.

Table 4. Tests of Normality (BT, PD, RM)

\begin{tabular}{ccccccc}
\hline & \multicolumn{3}{c}{ Tests of Normality } \\
\hline & \multicolumn{3}{c}{ Kolmogorov-Smirnov $^{\mathrm{a}}$} & \multicolumn{3}{c}{ Shapiro-Wilk } \\
\cline { 2 - 7 } & Statistic & Df & Sig. & Statistic & df & Sig. \\
\hline BT & .111 & 210 & .000 & .965 & 210 & .000 \\
PD & .251 & 210 & .000 & .845 & 210 & .000 \\
RM & .110 & 210 & .000 & .944 & 210 & .000 \\
\hline
\end{tabular}

a. Lilliefors Significance Correction

As per both Kolmogorov-Smirnov and Shapiro-Wilk test the Physicians prescription decision (PD) which is the dependent variable has reported being proven significant $\mathrm{P}=.000$ of having a normal distribution whereas prescribed value should be lesser than $\mathrm{P}=0.05$.

Further, Brand Trust (BT) which is the Independent variable has reported being proven significant $\mathrm{P}=.000$ of having a normal distribution whereas prescribed value should be lesser than $\mathrm{P}=0.05$.

Moreover, Relationship Marketing (RM) which is the moderating variable has reported being proven significant $\mathrm{P}=.000$ of having a normal distribution whereas prescribed value should be lesser than $\mathrm{P}=0.05$.

Table 5. Test of Homogeneity of Variances

\begin{tabular}{ccccc}
\hline & Levene Statistic & df1 & df2 & Sig. \\
\hline BT and PD & 8.489 & 14 & 194 & .0574 \\
RM and PD & 5.681 & 17 & 192 & .0514 \\
\hline
\end{tabular}

The assumption of homogeneity of variance is the second statistical assumption that needs to be tested for when comparing three or more independent groups on a continuous outcome with ANOVA.

As per the above table Homogeneity between Brand Trust And Physicians Prescription decision are found to be with a significance exceeding $\mathrm{P}=.05$. Thereby the independent and dependent variables are not found to be having a significance in the homogeneity of variance. Moreover, it doesn't violate the assumptions. Furthermore, Homogeneity between Physicians Prescription Decision and Relationship Marketing are also found to be with a significance exceeding $\mathrm{P}=.05$. Thereby the moderator and dependent variables are not found to be having a significance in the homogeneity of variance. Therefore, it doesn't violate the assumptions.

\section{Structural Model}

\section{Measurement Model Analysis}

Path coefficients are interpreted equivalently to a standardised beta weight in a multiple regression model (Gopal, Bostrom, \& Chin, 1992). Standardised path coefficients ideally should be between 0.20 and 0.30 to be meaningful (Chin, 1998a; Meehl, 1990). Kline (2005) however provides the following guidelines for new research with little theoretical or empirical basis from which to judge path coefficient effects: path coefficients less than 0.10 indicate a 'small' effect, values around 0.30 a 'medium' effect and values greater than 0.50 a 'large' effect (Bollen, 1989; Cohen, 1988; Pedhazur, 1982).

In the below models (Fig. II \& Fig. III) $\mathrm{R}^{2}$ of the path model showed 76.1 per cent for BT which indicates that the independent variables (BT) in model explains 79.8 per cent of the total variability of the dependent variable. The $\mathrm{R}^{2}$ value of 76.1 and 79.8 can be considered an indicator of the predictive validity of the overall model and 
represents a sufficient level to justify the goodness of fit of the present model. Chi-Square of the path model showed 0.034 for BT and PD 0.032 for PD and RM significance and as it's recorded lesser than P=0.05 it can be considered to be with acceptable significance. This represents a sufficient level to justify the goodness of fit of the present model.

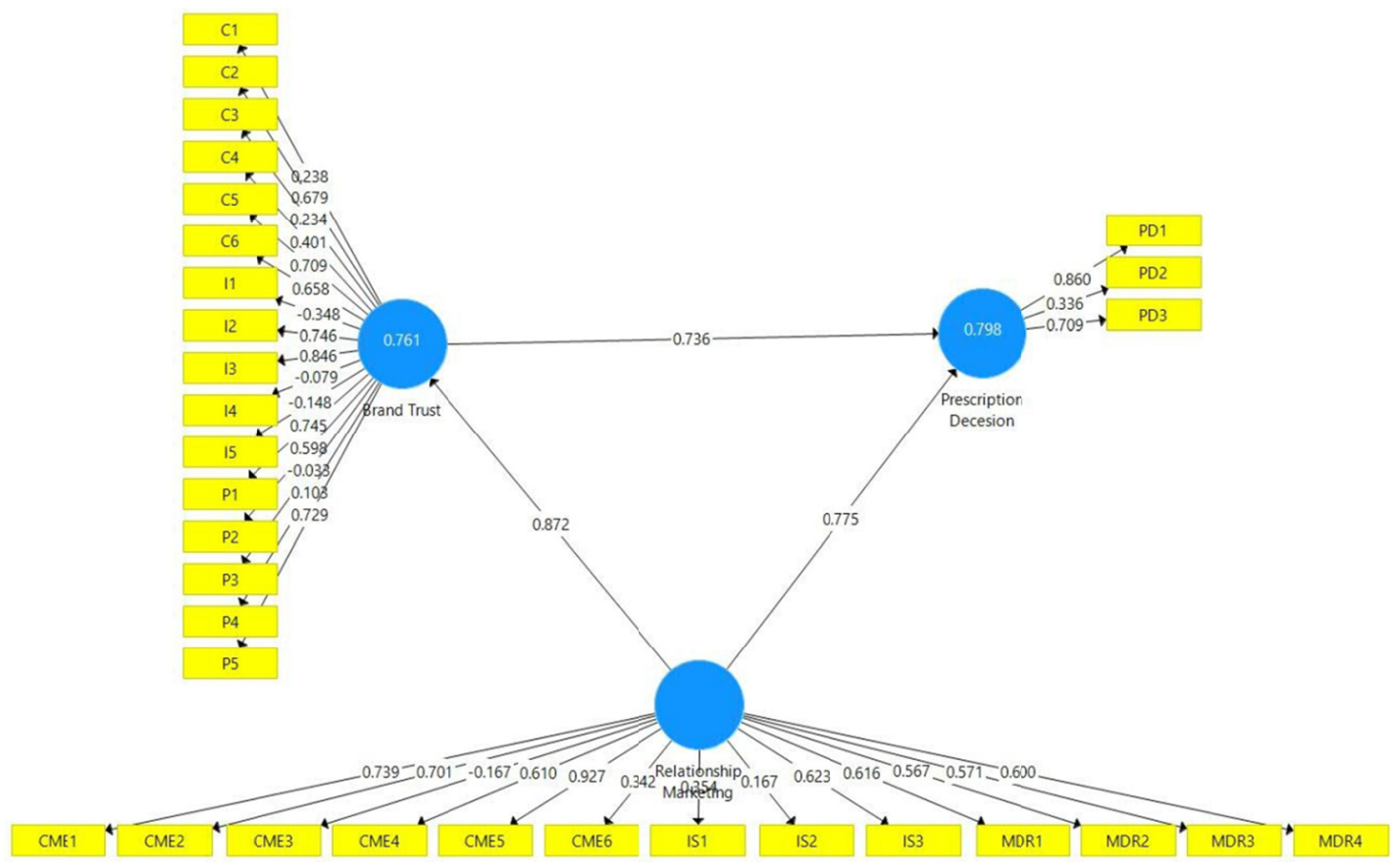

Figure 2. $\mathrm{R}^{2}$ Value

The result of bootstrapping indicate that the majority path coefficients are significant, $\mathrm{t}$ value of $\mathrm{C} \rightarrow \mathrm{BT}=35.211$ $(>1.96) ; \mathrm{P} \rightarrow \mathrm{BT}=33.570(>1.96) ; \mathrm{I} \rightarrow \mathrm{BT}=28.414(>1.96)$, which means there is a significant relationship between $\mathrm{C}$ and BT; P and BT; I and BT. Thereby it is evident all sub-variables have significant $t$ value over its main variable (Independent variable - BT). Further, the relationship between BT and PD has been proven with significant $t$ value of $4.874(>1.96)$ by enlarge prove $\mathrm{H} 1$ - Competence has a positive impact on Prescription Decision of PCC, H2 - Predictability has a positive impact on Prescription Decision of PCC, H3 - Benevolence /Integrity has a positive impact on Prescription Decision of PCC hypothesis giving a significant positive relationship 


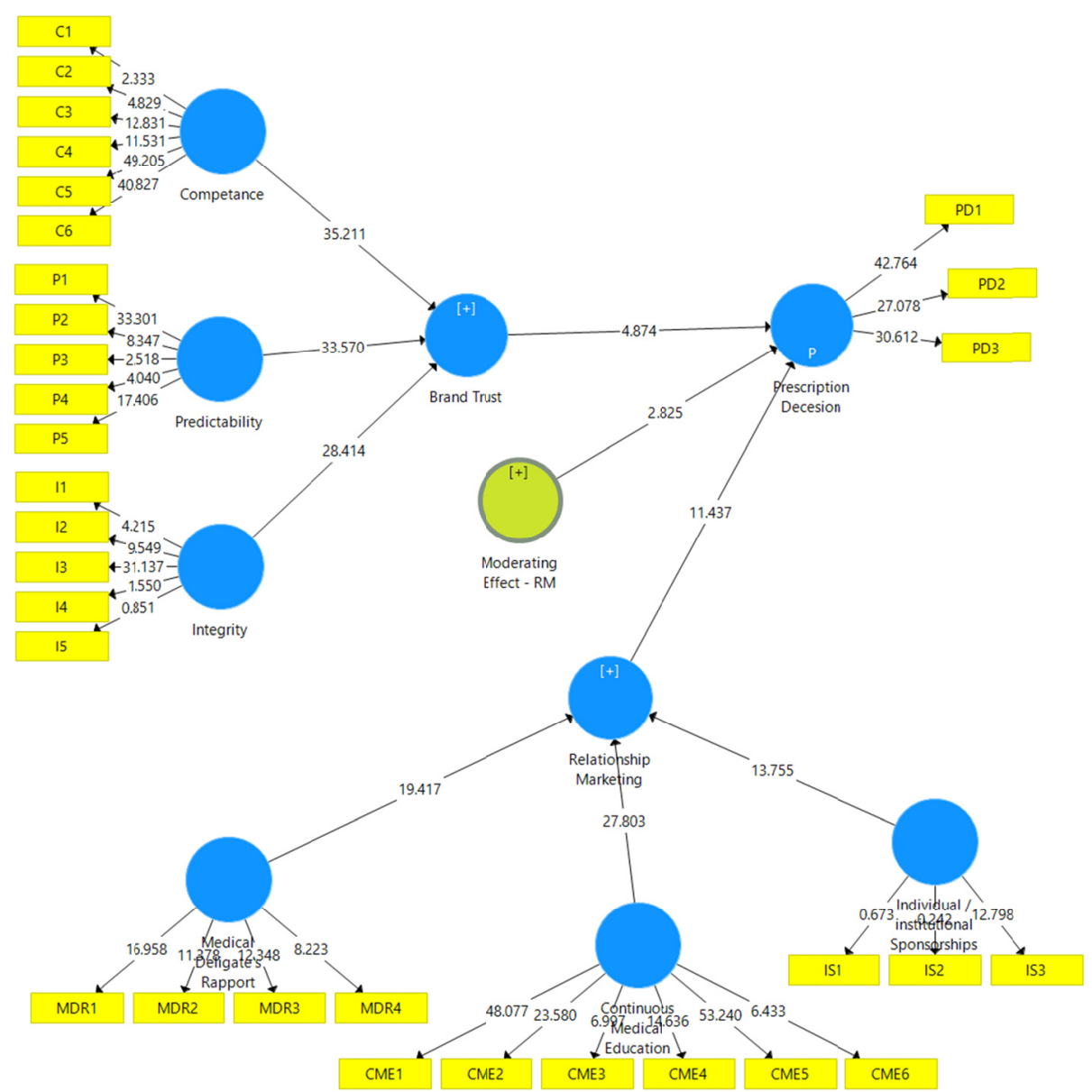

Figure 3. Path coefficient (beta) values

The $t$ value of the moderator 2.825 which is higher than 1.96 means RM strongly moderates the relationship between BT and PD. Therefore, H4 - Relationship Marketing has a Moderating effect on Relationship between Brand Trust and Prescription Decision of PCC hypothesis is proven.

The respective individual values are included in the summarized table below.

Table 6. Summarized Hypothesis Table

\begin{tabular}{clcl}
\hline Hypothesis & \multicolumn{1}{c}{ Relation } & Status & \multicolumn{1}{c}{ Justification } \\
\hline \multirow{2}{*}{$\mathrm{H} 1$} & $\begin{array}{l}\text { Competence has a positive impact on Prescription } \\
\text { Decision of PCC }\end{array}$ & Accepted & $\begin{array}{l}\mathrm{R}^{2}=0.761 ; \text { Correlation }=0.681 \\
(\mathrm{p}=0.000) ; \beta=35.211\end{array}$ \\
$\mathrm{H} 2$ & $\begin{array}{l}\text { Predictability has a positive impact on Prescription } \\
\text { Decision of PCC }\end{array}$ & Accepted & $\begin{array}{l}\mathrm{R}^{2}=0.761 ; \text { Correlation }=0.469 \\
(\mathrm{p}=0.000) ; \beta=33.570\end{array}$ \\
& $\begin{array}{l}\text { Benevolence /ntegrity has a positive impact on } \\
\text { Prescription Decision of PCC } \\
\text { Relationship Marketing has a Moderating effect on } \\
\text { Relationship between Brand Trust and Prescription }\end{array}$ & Accepted & $\begin{array}{l}\mathrm{R}^{2}=0.761 ; \text { Correlation }=0.238 \\
(\mathrm{p}=0.001) ; \beta=28.414\end{array}$ \\
& Decision of PCC & $\begin{array}{l}\mathrm{R}^{2}=0.798 ; \text { Correlation }=0.524 \\
(\mathrm{p}=0.000) ; \beta=2.825\end{array}$ \\
\hline
\end{tabular}

As per above table the researcher has proved all arrived hypotheses with reliable significance keeping with statistical guidelines stipulated by previous academic articles and meta-analysis respectively.

\section{Discussion}

With accordance to the empirical results given in above, brand trust-related elements such as competence, predictability, integrity have positive impact on the prescription decision of critical biological brands such as Octaplex (PCC). In contrast, it can be concretely stated that brand trust has highly significant impact on doctor 
endorsement on PCC. This is well proven with the results of correlation testing. Further, when studied on relationship marketing and its application in improving brand trust it was evident that RM had significant moderation impact on overall prescription decision of PCC in way of influencing doctors decision-making process via CMEs which enable doctors to receive a lot of vital and critical information on life-saving brand such as Octaplex. Similarly, medical representative rapport has equally enabled to support and increase doctors trust on the brand which was reconfirmation gained by this study in addition to the academic articles available. Finally, sub-elements such as institutional and individual sponsorships have too positively impacted to increase trust in the brand. In summary results obtained on moderation proves relationship marketing has significant positive moderation on the relationship of brand trust and prescription decision of PCC (Octaplex). This reflects that doctors consider brand trust and support of relationship marketing to be vital in importance once considering a prescription towards PCC or any other critical therapy.

\section{Managerial Implications}

The author wishes to emphasize that brand trust has very critical impact in generation of prescription decision for a biological product in this context for Octaplex, and marketing personal should follow brand trust elements and their implications very closely and construct them to get competitive advantage for Octaplex and the relationship marketing should be driven moderating set principals of brand trust. As Octaplex is a biological brand which is used for critical and life-threatening conditions the prescriber often faced high-risk decision when recommending the product there by an example sub-elements of brand trust play a significant role. for instance Competence the level of competence on brand from the doctor has shown very high importance as per the data analysis further when taken example like predictability the doctor has agreed that bio markers like having same outcome measures and clinical cure rates to be consistent among patients at all times. The application of the same in practice can be in ways of continual clinical trial discussions to emphasize the predicted outcome and frequent CME activities such as academic meeting and sessions to increase competence among peer doctors. And emphasize of proper End to End Cold Chain Management and GDP (Good Distribution Practice's) should be tools of promotion for doctors to improve their share of perception on brand trust.

As Doctors the practice implications can be vice versa as the study have layout the critical and integral parts of a Biological brands which are to be marketed. The doctors can request the Drug Companies to comply with set criteria which builds overall brand trust in which it will ease them to generate the prescription for Octaplex.in which doctors can request company and medical representatives to provide evidence in complying to GDP and Good Cold Chain Practices, for clinical research publications suggesting that Octaplex has similar or equivalent cure rate and desired clinical effect on all types of patients and they should further request for Institutional sponsorships in order to have international speakers to conduct lectures on the clinical significance of Octaplex as a Brand. Furthermore, practicing findings of the study is also made as a vital recommendation by author. In example if a marketing manager or a company strategize brand trust related campaigning for a biological product they should consider collaborating it with relationship marketing strategies to get a moderated and improved outcome to the overall brand trust campaign. And in this application for Biological brand the managerial implication is to develop marketing tools such as presentations, promotional brochures and storytelling align with ability of utilizing relationship marketing applications. Finally, areas newly understood where brand trust can be directly improved by relationship marketing collaboration such as providing Brand Information. And prompt response from Medical Delegates when doctor makes inquires assistance in brand Usage or demonstrations these areas should be properly looked and utilized.

\section{Limitations and Future Research Directions}

Researcher has constantly faced with the limitation of been unable to enrol the whole targeted doctor cohort to get total outcome. The demographic limitation was felt as limitations in level of clinical experience for Octaplex were low with certain specialties where the results can be mostly oriented to their point of view. Further as this study focus on a particular biological brand (Octaplex) the scope of the study can be seen as a limitation.

As the study layouts new theoretical framework for researchers now biological marketing research can be aligned towards the conceptualized model and the set applications can be further studied and as biological marketing research is in its primary stage the finding of this study can be emphasized and hypothesized in future research constructs. And same can be researched for other biological brands, pharmaceuticals and medical sector.

Furthermore, these implications of brand trust and moderations of relationship marketing can be used for disciplines and industries and sectors out of healthcare industry and it can measure how well these implications can be practiced in their own sectors. The moderation of relationship marketing was not identified as a such in any research till date under academic rigor, therefore the novel concepts can be used to gain better competitive 
advantage in arena of academic research itself.

Furthermore, due to findings of current study it can be applied to a further depth to understand and identify other related variables and dimensions which can be considered as moderators of Brand Trust, and due to comprehensive data analysis methods used, Future researchers of these constructs can adapt from these methodologies to mimic similar methodologies in their respective studies in area of hypothesis proving.

Thereby, researcher would make recommendation to conceptualizing same to other disciplines and industries and product portfolio and demography's to further reconfirm the frameworks laid out in this study on both brand trust and relationship marketing constructs, thereby reaching this finding to a greater apex.

\section{References}

Andrade, C., Shah, N., \& Chandra, S. (2007). The new patent regime: Implications for patients in India. Indian Journal of Psychiatry, 49(1), 56-59. https://doi.org/10.4103/0019-5545.31520

Annual Health Bulletin 2015. Ministry of Health: Ministry of Health, Nutrition and Indigenous Medicine.

Ballester, E. D., \& Alemán, J. L. M. (2001). Brand trust in the context of consumer loyalty. European Journal of Marketing, 35(11/12), 1238-1258. https://doi.org/10.1108/EUM0000000006475

Ballester, E. D., \& Alemán, J. L. M. (2005). Does brand trust matter to brand equity? European Journal of Marketing, 35(11/12), 1238-1258. https://doi.org/10.1108/10610420510601058

Bansal, H. S., Taylor, S. F., \& dan St. James, Y. (2005). Migrating to New Service Providers: Toward a Unifying Framework of Consumers' Switching Behaviors. Journal of the Academy of Marketing Science, 33(1), 96-115. https://doi.org/10.1177/0092070304267928

Barnes, M. L. (2003). Marketing to a Segment of One, Pharmaceutical Executive (p. 110).

Becerra, E. P., \& Badrinarayanan, V. (1992). The influence of brand trust and brand identification on brand Evangelism. Journal of Product \& Brand Management, 22(5/6), 371-383. https://doi.org/10.1108/JPBM-09-2013-0394

Business Monitor International (BMI). (2017). Sri Lanka Pharmaceuticals \& Healthcare Report. Business Monitor International a Fitch Group Company: BMI Research.

Carvalho, M. C., Rodrigues, A. G., Conceição, L. M., Galvão, M. L., \& Ribeiro, L. C. (2012). Prothrombin complex concentrate (Octaplex): A Portuguese experience in 1152 patients. Blood Coagul Fibrinolysis, 23(3), 222-228. https://doi.org/10.1097/MBC.0b013e328351250f

Chaudhuri, A., \& Holbrook, M. B. (2001). The chain of effects from brand trust and brand affect to brand Performance. Journal of Marketing, 65(2), 81. https://doi.org/10.1509/jmkg.65.2.81.18255

Elliott, R., \& Yannopoulou, N. (2007). The nature of trust in brands: A psycho-social model. European Journal of Marketing, 41(9/10), 988-998. https://doi.org/10.1108/03090560710773309

Geethanga, P. L. P., \& Dissanayake, D. M. R. (2014). Effectiveness of Relationship Marketing Tools on Building Brand Perception: With Reference to Surgery Transplant Products in Sri Lankan Pharmaceutical Industry. ICBI 2014 Conference Proceedings (pp. 181-196).

Giangrande, P. L. F. (2000). The History of Blood Transfusion. British Journal of Hematology, 110, 758-767. https://doi.org/10.1046/j.1365-2141.2000.02139

Hawass, H. H. (2010). Brand trust: Implications from consumer doubts in the Egyptian mobile phone market. Journal of Islamic Marketing, 4(1), 80-100. https://doi.org/10.1108/17590831311306363

Hegner, S. M., \& Jevons, C. (2016). Cross-national validation in Germany, India, and South Africa. Journal of Product \& Brand Management, 25(1), 56-68. https://doi.org/10.1108/JPBM-02-2015-0814

Hoffer, L. et al. (2005). Consistent manufacturing of 50 consecutive octaplex ${ }^{\circledR} 500$ lots: Biochemical characteristics of a prothrombin complex concentrate. Journal of Thromb Haemost, 3(1).

International Federation of Pharmaceutical Manufacturers \& Associations. (2017). The pharmaceutical industry and global health, facts and figures 2017.

Janakiraman, R., Dutta, S., Sismeiro, C., \& Stern, P. (2008). Physicians' persistence and its implications for their response to promotion of prescription drugs. Management Science, 54, 1080-1093. https://doi.org/10.1287/mnsc.1070.0799

Kachru, U. (2005). Strategic Management: Concepts and Cases. Excel Books. 
Karunanayake, R. K. T., \& Wanninayake, W. M. C. B. (2015). Impact of Key Purchasing Determinants on Purchase Intention of Hybrid Vehicle Brands in Sri Lanka, an Empirical Study. Journal of Marketing Management, 3(1), 40-52.

Lam, S. Y., Shankar, V., Erramilli, M. K., \& Murthy, B. (2004). Customer Value, Satisfaction, Loyalty, and Switching Costs: An Illustration from a Business-to-Business Service Context. Journal of the Academy of Marketing Science, 32, 293-311.

Lau, G. T., \& Lee, S. H. (1999). Consumers' Trust in a Brand and the Link to Brand Loyalty. Journal of Market Focused Management, 4(4), 341. https://doi.org/10.1023/A:1009886520142

Lewis, J. D., \& Weigert, A. (1985). Trust as a Social Reality. Social Forces, 63(4), 967-985. https://doi.org/10.1093/sf/63.4.967

Matzler, K., Krauter, S. G., \& Bidmon, S. (2008). Risk aversion and brand loyalty: The mediating role of brand trust and brand affect. Journal of Product \& Brand Management, 17(3), 154-162. https://doi.org/10.1108/10610420810875070

Medical Statistics Unit Ministry of Health, Nutrition and Indigenous Medicine. (2017).

Murshid, M. A., \& Mohaidin, Z. (2017). Models and theories of prescribing decisions: A review and suggested a new model. Pharmacy Practice (Granada), 15(2). https://doi.org/10.18549/PharmPract.2017.02.990

Murshid, M. A., Mohaidin, Z., \& Nee, G. Y. (2016). Moderating effects of contextual factors on relationship between pharmaceutical marketing strategies and physician prescription decision: A review. Tropical Journal of Pharmaceutical Research, 15(7), 1559-1568. https://doi.org/10.4314/tjpr.v15i7.28

Rampl, L. V., \& Kenning, P. (2014). Employer brand trust and affect: Linking brand personality to employer brand attractiveness. European Journal of Marketing, 48(1), 218-236. https://doi.org/10.1108/EJM-02-2012-0113

Sherriff, T. K., \& Yip, L. (2008). The moderator effect of monetary sales promotion on the relationship between brand trust and purchase behavior. Journal of Brand Management, 15(6). https://doi.org/10.1057/bm.2008.12

Sriwignarajaa, K., \& Fernando, P. M. P. (2015). Factors Affecting on Pharmaceutical Products Brand Promotions: A Study on Professional Endorsement Perspective (pp. 441-448). 6th International Conference on Business \& Information ICBI - 2015, Faculty of Commerce and Management Studies, University of Kelaniya, Sri Lanka.

Sung, Y., \& Kim, J. (2010). Effect of brand personality on brand trust and brand affect. Psychology \& Marketing, 27(7), 639-661. https://doi.org/10.1002/mar.20349

Tsang, J.-P. (2001). Micromarketing: An Individual Approach, Pharmaceutical Executive.

Wanninayake, W. M. C. B., \& Dissanayake, D. M. R. (2007). A comparative study of service quality and customer service in public sector and private sector commercial banks (pp. 268-274). In proceedings of $4^{\text {th }}$ International Conference of Business Management (ICBM), University of Sri Jayawardanapura, Sri Lanka, March 2007.

Wanninayake, W. M. C. B., \& Dissanayake, D. M. R. (2009). Impact of Developing Ethnocentric Brand Templates to Sustain the Local Brands-An Empirical Study (pp. 479-490). In proceedings of International Conference of Business Management (ICBM), University of Sri Jayawardanapura, Sri Lanka, March 2009.

\section{Copyrights}

Copyright for this article is retained by the author(s), with first publication rights granted to the journal.

This is an open-access article distributed under the terms and conditions of the Creative Commons Attribution license (http://creativecommons.org/licenses/by/4.0/). 